\title{
A STATISTICAL ANALYSIS OF 423 CONSECUTIVE PATIENTS ADMITTED TO THE SPINAL CORD INJURY CENTER, RANCHO LOS AMIGOS HOSPITAL, 1 JANUARY 1964, THROUGH 31 DECEMBER 1967*
}

\author{
By N. Elane Wilcox, Ph.D., E. Shannon Stauffer, M.D., and \\ VERNON L. NICKEL, M.D. \\ Spinal Cord Injury Center, Rancho Los Amigos Hospital, Downey, California \\ and University of Southern California School of Medicine, Los Angeles, California
}

THIS is a statistical description of a series of patients from a spinal cord injury centre providing care for civilian residents of the southwestern part of the continental United States. It is the first regional centre on the West Coast serving nonmilitary and non-veteran patients. The Long Beach Veterans Administration Hospital Spinal Cord Injury Center is also in Los Angeles County, California. This facility has an internationally recognised staff and programme, and has been providing treatment to spinal cord injured veterans for more than two decades following World War II.

Four hundred and twenty-three persons were admitted to the Spinal Cord Injury Center at Rancho Los Amigos Hospital, Downey, California, for rehabilitation between I January I964, and 3I December 1967. These were adult patients (at least I 5 years of age) with spinal cord lesions resulting in varying degrees of motor and sensory paralysis.

This report documents causes of trauma, levels of paralysis, sex, age, duration of hospitalisation, and mortality figures for the period of initial hospitalisation at this Center. It is the first of a series of papers which will deal with thecontinuing experience of the Center as a unit, and of follow-up of patients after discharge. This study indicates the annual change in size of the case load at the Center, and the patients' geographical place of residence at the time of initial admission. It projects the influence of sensory and motor dysfunction upon the post-hospital phase of the patient's life as reflected by the cause and frequency of outpatient clinic visits and re-admissions to the Center.

Source of Patients in Rancho Los Amigos Hospital Spinal Cord Injury Center (Geographic). Patients on the spinal cord injury programme are predominantly Los Angeles County, California, residents. This is predictable because Rancho Los Amigos Hospital is the rehabilitation facility of the eight hospitals comprising the Los Angeles County Department of Hospitals.

With the inception of a Research and Demonstration Grant from the Social and Rehabilitation Service of the United States Department of Health, Education, and Welfare, the Regional Rehabilitation Center began to function on I April I966, offering services not only to the residents of California outside of Los Angeles County, but also to those of adjacent states. Distribution by residence is indicated in Figures I, 2 and 3.

* The centre described in this paper was supported in part by a Social and Rehabilitation Services Grant (RD 3012-M-69). 


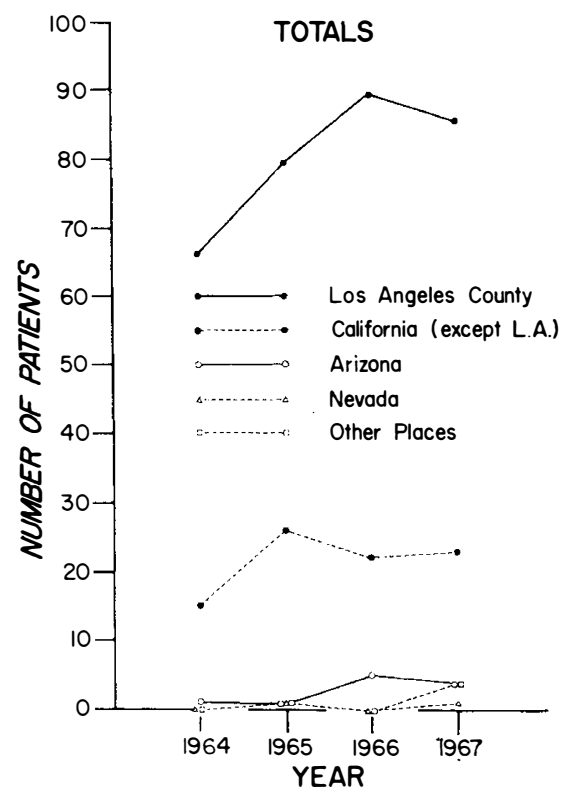

FIG. I

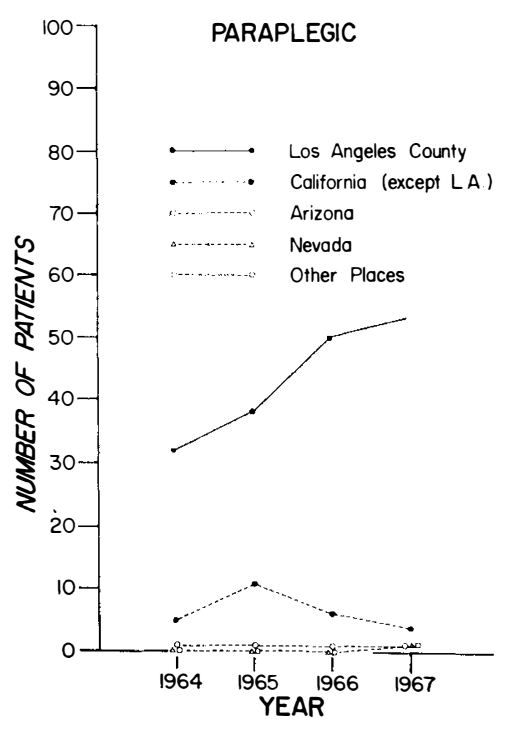

FIG. 2

Fig. I.-Scoliosis secondary to spastic paraplegia. Note extreme rotation.

Fig. 2.-Distribution by residence and level of injury (paraplegics).

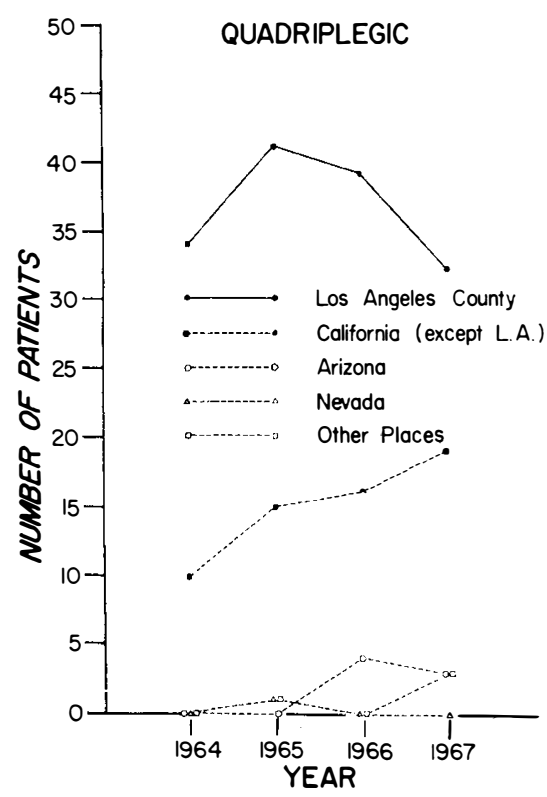

Fig. 3.-Distribution by residence and level of injury (quadriplegics)

FIG. 3 
Development of the Service: Concept of Modules Applied. In I96I a specially designed building was opened at Rancho Los Amigos Hospital to care for spinal cord injured patients. The capacity of this one-storey structure is 120 beds and includes treatment areas, offices, and other special facilities. At the time of its planning, it was believed that approximately 120 beds would be needed to meet the needs of spinal cord injured patients of Los Angeles County. Because improvements in care resulted in fewer complications and reductions of periods of immobility, the time of hospitalisation by actual experience proved to be shorter. The original estimated hospital stay was based on previously circulated data and prevalent opinion.

When this study began in I964, 4I beds were allotted to the Spinal Cord Injury Service. This number rose to 52 in 1966, and to 60 in 1967. In I968 the Center again expanded to its present total of 75 beds. This growth reflects the constantly increasing demand by residents of Los Angeles County, the state of California, and adjacent states for the specialised rehabilitation service offered here.

It is the conclusion of personnel of this Center after four years' experience that a modular concept provides the best care for patients with these complex problems. A module consists of 30 beds, each with its own professional staff of physicians, nursing personnel, therapists, medical social workers, and clinical psychologists. Experience has shown that this plan lends itself to more accurate staff and fiscal accounting, as well as more personalised patient care.

Duration of Hospitalisation. Figure 4 indicates the duration of hospital stay of a consecutive series of I88 patients treated in the Center from January 1965, through December 1967, admitted within six months following injury. There has been relatively little change in the number of days' hospitalisation required for this type of patient. One patient admitted with pressure sores accounted for the upper columns in I966. He was hospitalised for a total of 547 days to heal these ulcers. The next highest number of days of hospitalisation that year was 307 (fig. 4).

Rancho Los Amigos Hospital does not receive emergency cases. All new injuries are seen in acute hospitals and referred to this Center when their physical condition has stabilised. A large number of these referrals are from the Los Angeles County-University of Southern California Medical Center. (This Medical Center and Rancho Los Amigos Hospital are facilities of the Los Angeles County Department of Hospitals with many staff members holding appointments at both hospitals.) The Chief of the Spinal Cord Injury Center makes regular rounds in the Intensive Care Unit at the Medical Center seeing new injuries before they are released from their immediate post-injury treatment.

Traumatic and Non-traumatic Lesions: Distribution. Figures 5 and 6 indicate the relative frequency of traumatically and non-traumatically produced lesions, and shows the distribution of cases by sex. Although most of the cases treated were traumatic, this series included 75 non-traumatic lesions of the cord. Etiology of non-traumatic lesions includes: tumours, 30 (I 8 females, I 2 males); seriously complicated herniated discs, 8 (4 females, 4 males); spondylosis, 6; syringomyelia, 2; tuberculosis of the spine (Pott's Disease), 2; and osteomyelitis, 2. Other non-traumatic lesions were due to a variety of causes including obscure and incompletely defined diagnoses. 


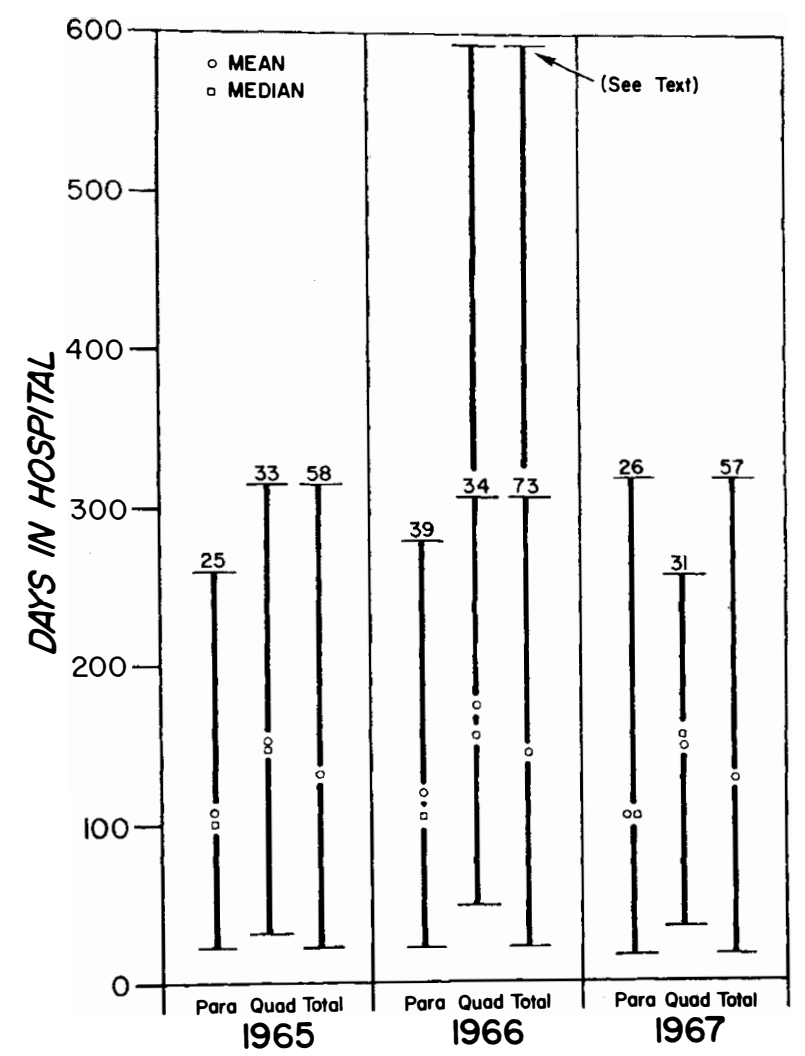

Fig. 4.-Duration of hospital stay (days). I88 patients admitted with six months of injury.

Fig. 5.-Traumatic injuries: distribution by sex.

Fig. 6.-Non traumatic injuries: distribution by sex.

FIG. 4

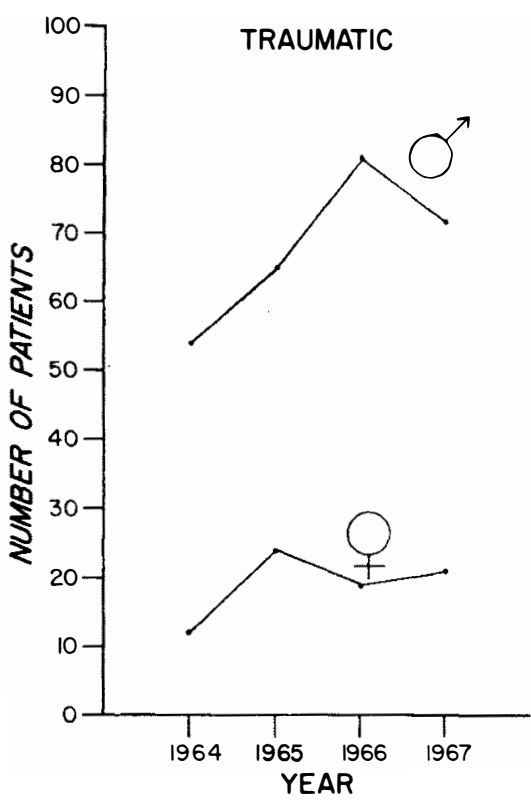

FIG. 5

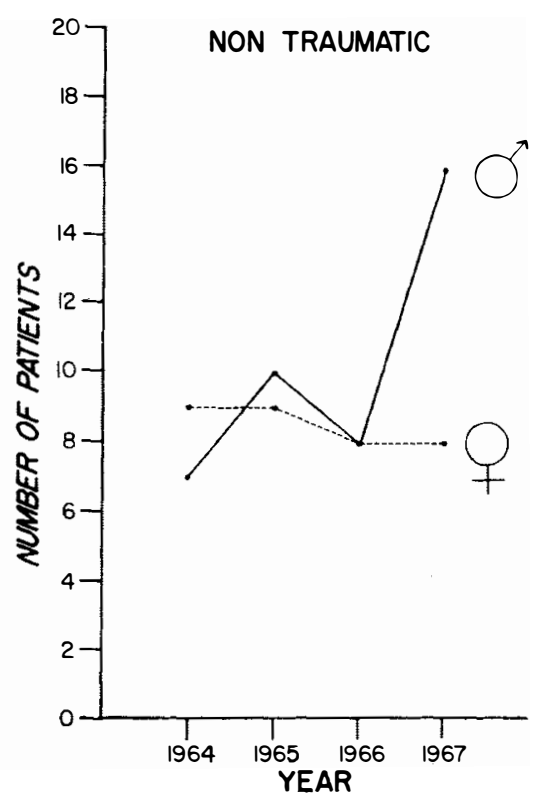

FIG. 6 


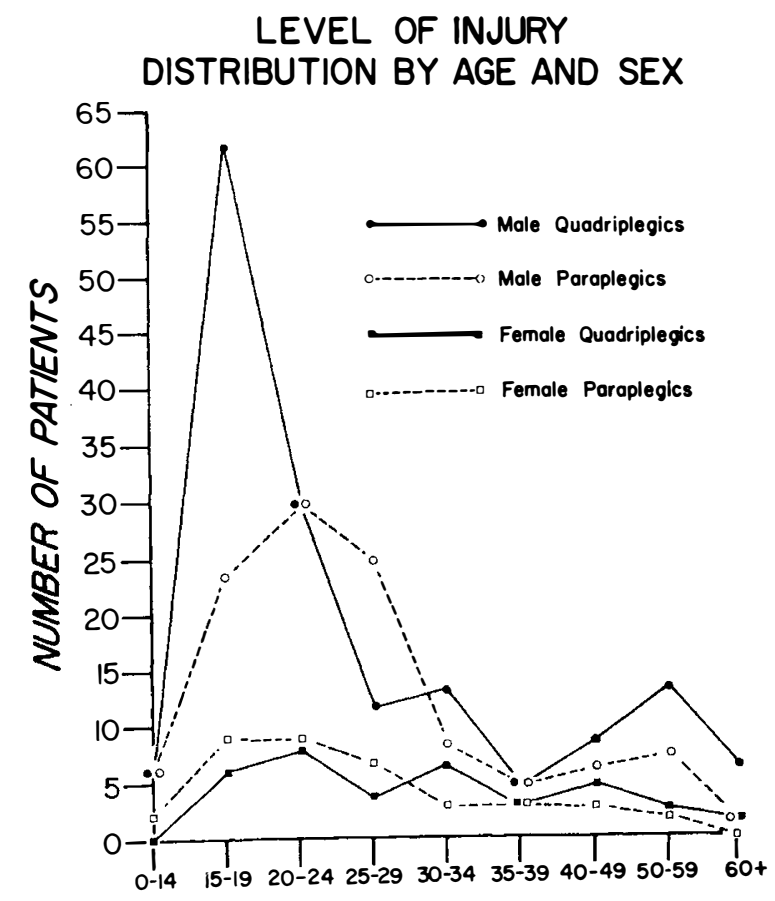

FIG. 7

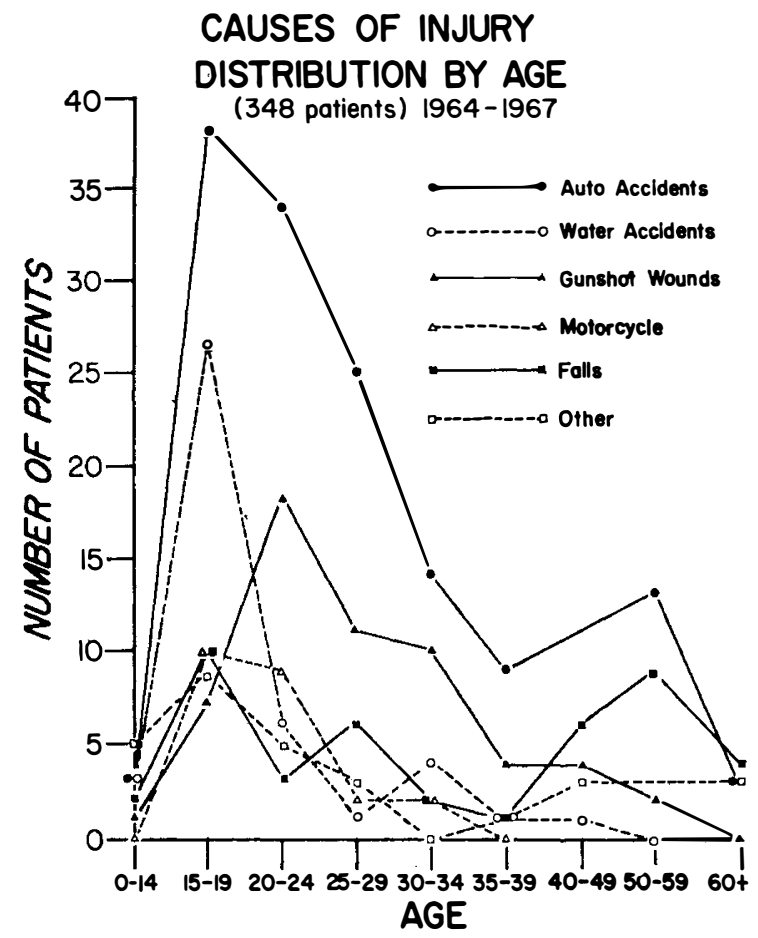

FIG. 8 
This series included $4 \mathrm{I}$ males and 34 females of which 54 were paraplegic and 2I quadriplegic.

Figure 7 documents the causes of injury and the age at which most of these injuries occurred.

Figure 8 shows the level of injury and the sex distribution.

Re-admission and Out-patient Clinical Experience of the Center. Patient case load in all categories of care (initial admission, re-admission, and clinic visits) has increased steadily during the past four years. Complete figures for

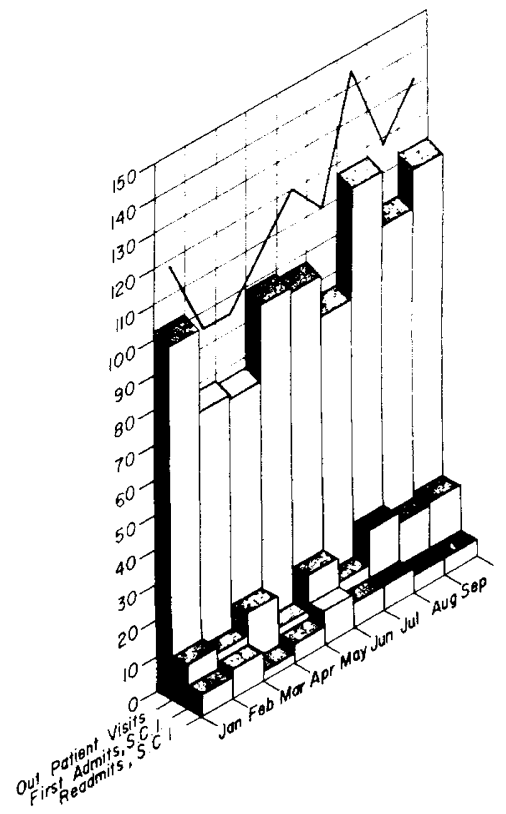

FIG. 9

Relative frequency of first admissions, re-admissions and out-patient clinic visits, January-September 1968. -(Solid line represents total admissions.) out-patient clinic visits are not available for the entire period covered by this study, but Figure 9 shows relative frequency of first admissions, re-admissions, and clinic visits for nine months in 1968.

Table I classifies distribution of re-admissions to the Center by incidence and reason for re-admission for 1967. The table does not include all re-admissions to the hospital for genito-urinary problems since they are cared for on the G.U. Service. It is obvious that much better records of out-patient care must be maintained; however, our experience indicates that better out-patient care will probably reduce the numbers of re-admissions for complications, especially genito-urinary complications.

The frequency of re-admissions shown in Table I also reflects increased reconstructive surgery (upper and lower extremity muscle and tendon transfers for increased function), admissions for training in functional rehabilitation (ambulation training, improvement in hand function following surgery, and driver training), and a higher incidence of anterior and posterior spinal fusions for late instability. Existing records reveal that the causes for readmissions are changing. Rather than as many patients returning for care of problems which should never have happened (pressure sores and contractures), some are now being re-admitted for more positive programmes such as reconstructive surgery. It is obvious that the major cause for patients returning to this Center is pressure sores. See Table II for mortality figures.

\section{DISCUSSION}

I. A major objective of the Spinal Cord Injury Center is to develop a meaningful programme to prevent injuries. First and ideal, of course, would be prevention of the initial accident. Second, would be prevention of aggravation of the orthopaedic injury (or bony trauma) immediately following or even later, leading to 


\section{TABLE I}

Distribution of Patient Population (423) by Year, Identified by Level of Injury, Sex and Traumatic or Non-traumatic

\begin{tabular}{|c|c|c|c|c|c|}
\hline & & raplegia $=$ & $7(48 \cdot 94$ & & \\
\hline & Tra & latic & Non- & umatic & \\
\hline & Male & Female & Male & Female & Total \\
\hline I964 & 23 & 4 & 5 & 6 & $3^{8}$ \\
\hline 1965 & 25 & I4 & 5 & 6 & 50 \\
\hline I966 & 36 & 8 & 5 & 8 & 57 \\
\hline I967 & $3 \mathrm{I}$ & I 2 & I 2 & 7 & 62 \\
\hline & $\begin{array}{c}\text { II } 5 \\
(75.2 \%)\end{array}$ & $\begin{array}{c}38 \\
(24 \cdot 8 \%)\end{array}$ & $\begin{array}{c}27 \\
(50 \%)\end{array}$ & $\begin{array}{c}27 \\
(50 \%)\end{array}$ & 207 \\
\hline & & driplegia $=$ & $6(5 \mathrm{I} \cdot \mathrm{O}$ & & \\
\hline & Tra & atic & Non- & imatic & \\
\hline & Male & Female & Male & Female & Total \\
\hline I964 & $3 I$ & 8 & 2 & 3 & 44 \\
\hline 1965 & 40 & IO & 5 & 3 & 58 \\
\hline I966 & 45 & I I & 3 & 0 & 59 \\
\hline I967 & $4 \mathrm{I}$ & 9 & 4 & I & 55 \\
\hline & $\begin{array}{c}\text { I } 57 \\
(80.5 \%)\end{array}$ & $\begin{array}{c}38 \\
(19.5 \%)\end{array}$ & $\begin{array}{c}\text { I4 } \\
\left(67^{\circ} \%\right)\end{array}$ & $\left(\begin{array}{c}7 \\
(33 \%)\end{array}\right.$ & 216 \\
\hline
\end{tabular}

\section{TABLE II}

Initial Hospitalisation, Rancho Los Amigos Hospital Terminated by Death

Traumatic Injuries .

Non-traumatic Lesions . . . . . $5^{\dagger}$

* I-Paraplegic from self-inflicted gunshot wound: Suicide I-Paraplegic, 35 years duration, from auto accident: Carcinomatosis

I-Quadriplegic, four and one-half months duration, from beating: Pulmonary emboli and pneumonia

$\dagger$ 4-Paralysis due to malignant neoplasms resulting in death.

I-Paralysis from t.b.c. abscess; dead of liver failure, cirrhosis.

C 
possible cord trauma, and occurring during the course of emergency evacuation following the accident or in the course of treatment. Third, and equally important, is to prevent complications, such as pressure sores, urinary infections, and contractures.

Spinal cord injuries, considered by time of occurrence as related to the associated traumatic encounter, can be classified as

(a) Concomitant Cord Lesions. Those in which cord lesion is a result of the initial impact causing immediate paralysis; and

(b) Sequential Cord Lesions. Those occurring at some time after initial impact and caused by abnormal motion of broken or displaced bony structures resulting in trauma to the cord.

There can be a serious bony lesion without any neurological deficit; any increase in neurological deficit following the initial trauma is cause to consider a possible sequential cord trauma.

2. The phenomenal improvement in survival rates of war casualties following World War II resulted from intervention to allay and control urinary complications previously responsible for deaths among many cord injured persons. Prevention of pressure sores is an entirely possible goal. An effective educational programme directed to patients, attendants, and hospital personnel which will result in significantly reducing these complications is badly needed. The staff at Rancho Los Amigos Hospital has been forced to expend a major part of its time to heal pressure sores which can be and should have been prevented.

3. Early admission to spinal cord injury centres following injury would obviate an unnecessary expenditure of time, money, and suffering involved in correcting complications. Personnel alert to these potential hazards are best suited to care for the spinal cord injured patient. These observations emphasise the great need to establish closer liaison between the acute hospital and the rehabilitation centre.

The average number of days between the date of trauma and the date of admission to the Spinal Cord Injury Center at Rancho Los Amigos Hospital for all 'new' injuries admitted during the first four months of 1969 was 38 . The range was from 2 to 183 days. 'New' injuries refer to those persons admitted from an acute hospital thus affording continuous care from initial admission following injury. Other admissions include re-admissions to the Center, transfers from other rehabilitation, convalescent, or long-term facilities, or from the patient's home. Eleven of the 30 new injuries arrived with pressure sores; 26 had urinary infections. Two of the patients admitted free of urinary infections had incomplete lesions and did not have catheters; a third was admitted on an intermittent catheterisation programme. The fourth, an 83-year-old female victim of an automobile accident, died within 48 hours of admission and laboratory studies were not completed.

4. Patients in this series are currently being evaluated for long-term results and residuals following early operations. Findings will be reported in subsequent statistical and clinical studies.

\section{SUMMARY}

The authors of this report are convinced that many more civilian centres are needed and that they should be strategically placed throughout the country to make 
them geographically accessible to all persons in the United States. The recommended number of beds in a Centre is a minimum of 25 , but not over 90 to 100 .

This report provides no cause for complacency; rather it focuses upon the need for more centres to treat patients; for more effective safety and accident prevention programmes; and for better reporting of case histories by both acute and rehabilitation institutions. It challenges the experience and interest of trained professional personnel to anticipate, propose, and execute studies which will identify, document, follow, and evaluate care of spinal cord injuries. More comprehensive publication of findings is needed to furnish guidelines for improved care, education, and prevention.

\section{RÉSUMÉ}

Les auteurs de ce rapport sont convaincus que des Centres pour traumatisés médullaires civils sont nécessaires et qu'ils pourraient être distribués d'une façon stratégique à travers le pays, de façon à ce qu'ils soient accessibles pour tous aux Etats-Unis. Le nombre de lits recommandé pour un centre est au minimum de 25 mais cependant pas au-dessus de 90 à IO०.

Ce rapport ne donne aucune raison de complaisance, mais au contraire, indique une nécessité d'un plus grand nombre de centres pour soigner ces malades; aussi, pour des programmes de prévention plus effectifs et une meilleure étude des observations dans les institutions destinées à la phase aiguë et à la réadaptation; elle fait appel à l'experience et à l'intérêt du personnel dans la profession, pour anticiper, proposer et exécuter des études qui pourront s'identifier, documenter, suivre et évaluer les soins aux traumatisés médullaires.

Des publications plus compréhensives sont demandées de façon à améliorer ces soins, l'éducation, et même la prévention.

\section{ZUSAMMENFASSUNG}

Die Autoren dieses Berichtes sind überzeugt, dass viel mehr Zentren für Zivilisten notwendig sind und dass diese strategisch durch das Land plaziert werden sollen, um sie geographisch allen Personen in den Vereinigten Staaten von Amerika zugänglich zu machen. Sie schlagen als Minimum eines Zentrums 25 Betten vor, aber die Zahl der Betten soll nicht 90-100 überschreiten.

Dieser Bericht gibt keinen Grund für Selbsgefälligkeit, im Gegenteil er betont die Notwendigkeit von mehr Zentrums für die Behandlung von Patienten, weiterhin eine mehr effektive Sicherheit und Vorbeugungsmassnahmen für Unfälle und ferner bessere Abfassung von Krankengeschichten sowohl in Institutionen der akuten Behandlung wie der Rehabilitation. Er fordert die Erfahrung und Interest von trainierten professionellen Personal. um Studien vorauszusehen, vorzuschlagen und auszuführen, welche $\mathrm{zu}$ einer Identifizierung und Abschätzung der Behandlung von Rückenmarksverletzungen führen. Mehr umfassende Veröffentlichungen von Ergebnissen sind notwendig, um als Wegweiser für Behandlung, Ausbildung und Verhütung zu dienen.

\section{REFERENCE}

Guttmann, Sir Ludwig (1967). History of the National Spinal Injuries Centre, StoekMandeville Hospital, Aylesbury. Paraplegia, 5, II5-I26. 